\title{
G.B. Morgagni Prizes 2012
}

\section{Gaetano Crepaldi}

(C) Springer-Verlag 2011

The "G.B. Morgagni Prizes" are awarded under the auspices of the School of Medicine of the University of Padua and supported by an unrestricted educational grant from SERVIER.

The prizes, consisting of one Morgagni Medal (gold medal and 20,000 Euros) and two Young Investigator Awards (silver medal and 8,000 Euros), are conferred every 2 years for outstanding achievements in basic and clinical research in the field of diabetic and metabolic disorders.

Nominations are now open for the Morgagni Medal that will be awarded to a distinguished European scientist actively involved in original and innovative investigations in the field of diabetes and its complications.

Each candidate for the gold medal should be nominated by at least two individuals who should provide the nominee's curriculum vitae and supporting statements of not more than 500 words.
Applications are also invited from young European scientists (not yet 40 on January 1, 2012) who should forward a brief letter of application, curriculum vitae, list of publications and reprints of their five most important manuscripts.

The G.B. Morgagni Prize winners will be presented during a symposium on metabolism, which will be held in Padua (Italy) on October 19, 2012, and the recipient of the Morgagni Medal will present a lecture during the Awards Ceremony.

Nominations for the G.B. Morgagni Medal and applications for the Young Investigator Awards must reach our offices by February 29, 2012. Documents may be forwarded by surface mail to the address below or by e-mail (saved in RTF). Reprints should be sent only by post.

G. Crepaldi ( $\square)$

The G.B. Morgagni Prizes, C.N.R. Istituto di Neuroscienze, Sezione Invecchiamento, Via Giustiniani 2, 35128 Padova, Italy e-mail: crepaldi.metabolism@unipd.it 